CORRECTION

\title{
Correction: Associations between changes in precerebral blood flow and cerebral oximetry in the lower body negative pressure model of hypovolemia in healthy volunteers
}

Jonny Hisdal, Svein Aslak Landsverk, Ingrid Elise Hoff, Ove Andreas Hagen, Knut Arvid Kirkebøen, Lars Øivind Høiseth

Fig 2, "Measurements," appears as a duplicate of Fig 1. Please view the correct Fig 2 here.

Citation: Hisdal J, Landsverk SA, Hoff IE, Hagen OA, Kirkebøen KA, Høiseth LØ (2019) Correction: Associations between changes in precerebral blood flow and cerebral oximetry in the lower body negative pressure model of hypovolemia in healthy volunteers. PLoS ONE 14(7): e0220403. https:// doi.org/10.1371/journal.pone.0220403

Published: July 23, 2019

Copyright: ๑ 2019 Hisdal et al. This is an open access article distributed under the terms of the Creative Commons Attribution License, which permits unrestricted use, distribution, and reproduction in any medium, provided the original author and source are credited. 


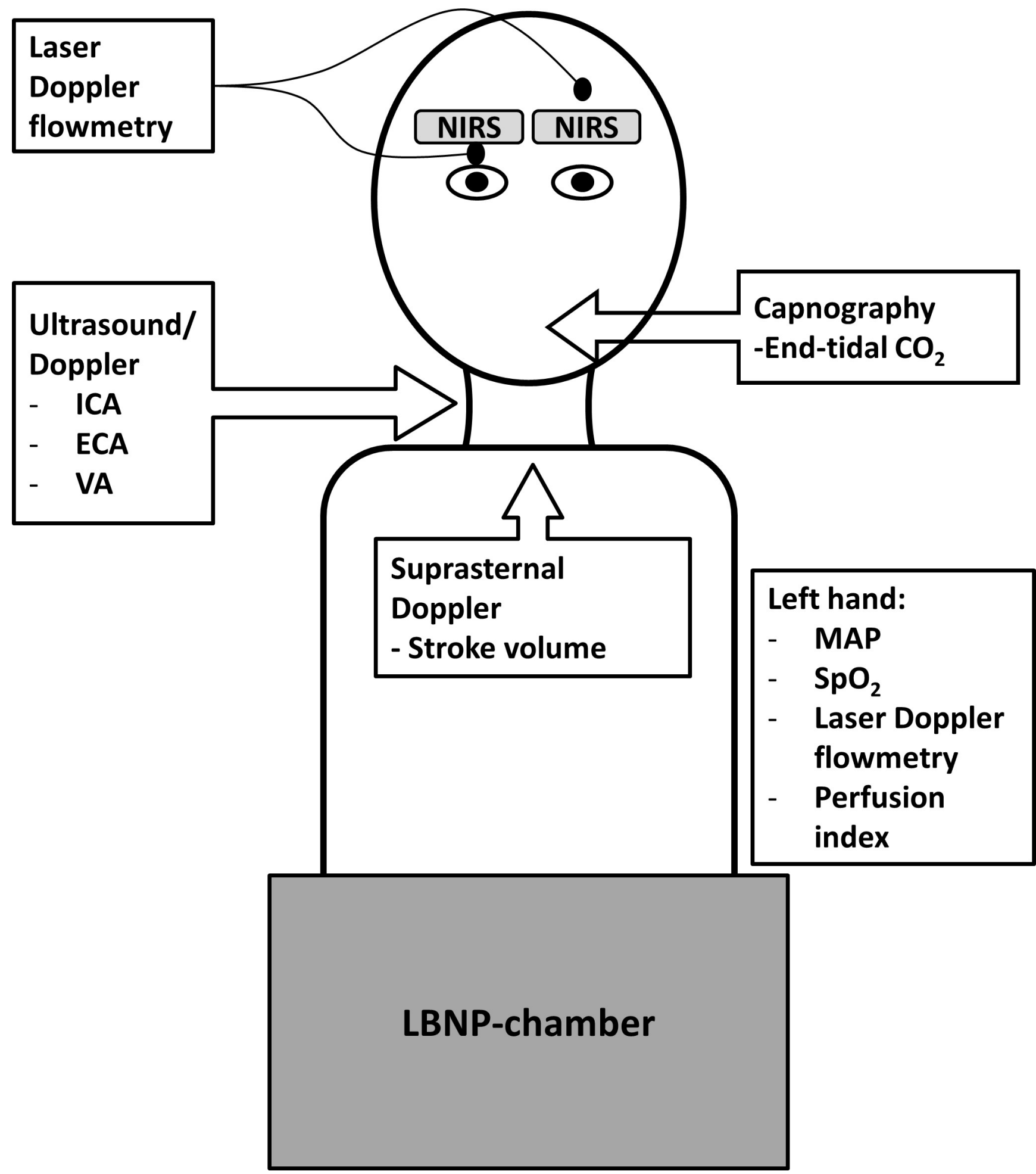

Fig 2. Measurements. Schematic overview of the performed measurements. 


\section{PLOS $\mid$ ONE}

\section{Reference}

1. Hisdal J, Landsverk SA, Hoff IE, Hagen OA, Kirkebøen KA, Høiseth LØ (2019) Associations between changes in precerebral blood flow and cerebral oximetry in the lower body negative pressure model of hypovolemia in healthy volunteers. PLoS ONE 14(6): e0219154. https://doi.org/10.1371/journal.pone. 0219154 PMID: 31251778 